Article

\title{
Bidirectional Resonant Converter with Half-Bridge Circuits: Analysis, Design, and Implementation
}

\author{
Bor-Ren Lin * (1) and Guan-Yi Wu \\ Department of Electrical Engineering, National Yunlin University of Science and Technology, Yunlin 640, \\ Taiwan; m10512006@yuntech.edu.tw \\ * Correspondence: linbr@yuntech.edu.tw; Tel.: +886-912-312-281
}

Received: 24 April 2018; Accepted: 14 May 2018; Published: 15 May 2018

check for updates

\begin{abstract}
A soft-switching dc-dc converter with bidirectional power flow capability is studied in this paper for energy storage units or electric vehicle applications. The circuit topology of the studied converter is constructed using a dual half-bridge circuit with split capacitors. A series resonant tank with frequency control modulation is employed in the proposed circuit to realize the soft switching characteristics of active devices. Synchronous-rectifier-based Metal-Oxide-Semiconductor Field-Effect Transistor (MOSFETs) are used on the low-voltage side to lessen conduction loss on the power semiconductors. The benefits of the studied circuit are bidirectional power flow capability, high efficiency, low switching loss, and simple circuit structure. The achievability of the developed converter is demonstrated from test results with a scaled-down laboratory prototype.
\end{abstract}

Keywords: resonant circuit; bidirectional power flow; zero-voltage switching; half-bridge circuit

\section{Introduction}

Clean energy sources have been developed to lessen the demand of fossil fuel, reduce environmental air pollution, and decrease climate change. Therefore, power-electronics-based energy conversion has been researched and studied to increase energy conversion efficiency and reduce circuit size. For ac or dc microgrid systems [1-5], dc/dc converters, ac/dc converters, and dc/ac converters are needed to integrate the utility power, wind power, solar power, energy storage units, and residential loads. For electric vehicles [6-9], ac/dc converters are employed for the battery charger, $\mathrm{dc} / \mathrm{dc}$ converters are adopted on the dc power distributing system, and dc/ac converters are used for ac motor drives. Bidirectional dc/dc converters [10-15] are widely used for battery-based energy storage units in dc microgrid systems and electric vehicles. Normally, bidirectional dc/dc converters are adopted to transfer electric energy between high voltage dc buses and energy storage units. Among the circuit topologies of bidirectional dc/dc converters, the half-bridge topologies and full-bridge topologies are most attractive solutions to realize bidirectional power flow capability. Phase-shift pulse-width modulation (PWM) is usually selected in full-bridge converters. However, high circulating current losses and high switching losses on light load are the main shortcomings. Resonant converters [16-19] with frequency modulation have been studied to achieve soft switching characteristics and bidirectional power flow capability. However, the circuit characteristics under forward and reverse power flow directions are different. Thus, the design procedures of bidirectional resonant converters are more difficult. In [16], the characteristic of a series resonant converter was achieved in forward power flow (or buck operation). However, the characteristic of a series resonant converter cannot be achieved at the whole load range in reverse power flow (or boost operation) due to the circuit topologies in the buck and boost operations not being symmetric circuits. In [17-19], the circuit topologies with half-bridge or full-bridge converters in both power flows are symmetric so that the power devices can be turned on under zero voltage and low switching losses. However, 
one more inductor is connected to the switching leg so that high circulating current is introduced and conduction losses are increased. Therefore, the circuit efficiency is reduced.

A bidirectional dc/dc converter with a frequency modulation scheme is studied to realize the features of bidirectional power flow capability and zero-voltage switching. A dual half-bridge circuit is used in the studied circuit to realize bidirectional power flow. A series resonant tank is adopted on the high-voltage side to realize the soft switching characteristics for all active devices. Synchronous rectifiers are used on the low-voltage side to further reduce the conduction loss. In order to realize the same resonant characteristics under forward and reverse power flow directions, an ac power switch and parallel inductor are connected to the half-bridge leg on the high-voltage side. The proposed circuit and the conventional bidirectional resonant converters in [17-19] have the same resonant component counts. However, the proposed converter has less circulating current loss due to the fact that the parallel inductor is disconnected under forward power flow. The circuit topology of the studied circuit is simple and easy to implement. In Section 2, the circuit configuration, operating stages, and circuit characteristics of the proposed converter are discussed. In Section 3, the design procedures of the developed converter are provided. Experimental waveforms are demonstrated in Section 4, and conclusions are discussed in Section 5.

\section{Proposed Converter}

The circuit schematic of the studied dual half-bridge converter is provided in Figure 1 to realize bidirectional power flow. Two half-bridge circuits are used on both the high- and low-voltage sides and one resonant tank is adopted on the high-voltage side to achieve the soft switching characteristic under frequency control. If power is transferred from high-voltage $V_{1}$ to low-voltage $V_{2}$ as shown in Figure 2a, the ac switch $S$ is open and the dual half-bridge converter is worked under buck mode operation. $Q_{1}$ and $Q_{2}$ are main power devices and $Q_{3}$ and $Q_{4}$ are operated as synchronous rectifiers. $L_{r}, C_{r}$, and $L_{m 1}$ are operated as an $L L C$ resonant converter to have low switching losses and high circuit efficiency functions. If power is transferred from low-voltage $V_{2}$ to high-voltage $V_{1}$ as shown in Figure $2 \mathrm{~b}$, the ac switch $S$ is closed and the dual half-bridge converter is worked under boost mode operation. Under this condition, $Q_{3}$ and $Q_{4}$ are the main power devices, $Q_{1}$ and $Q_{2}$ are off, and the antiparallel diodes are worked as the full-wave rectifier. $L_{r}, C_{r}$, and $L_{m 2}$ are operated as an $L L C$ resonant converter to give low switching losses and high circuit efficiency functions.

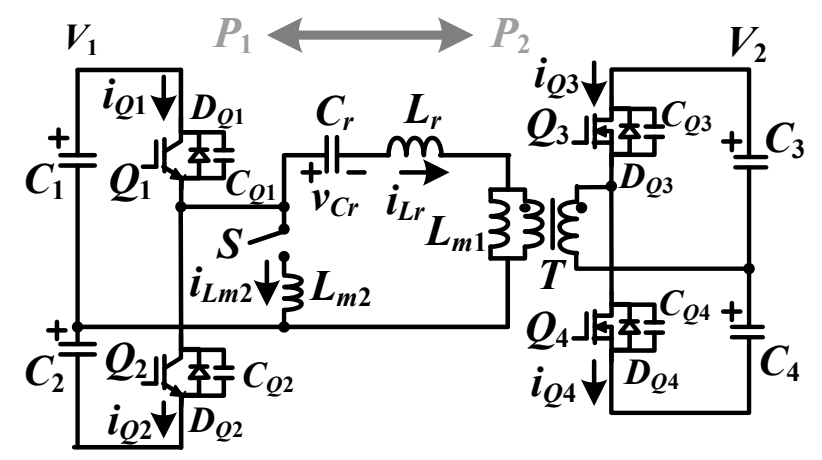

Figure 1. Circuit schematic of the proposed dual half-bridge converter. 


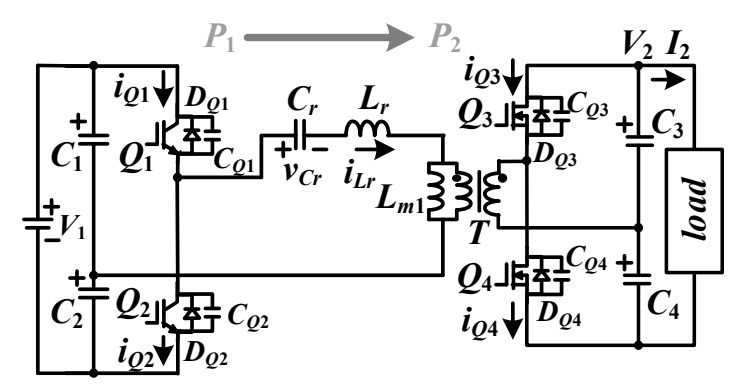

(a)

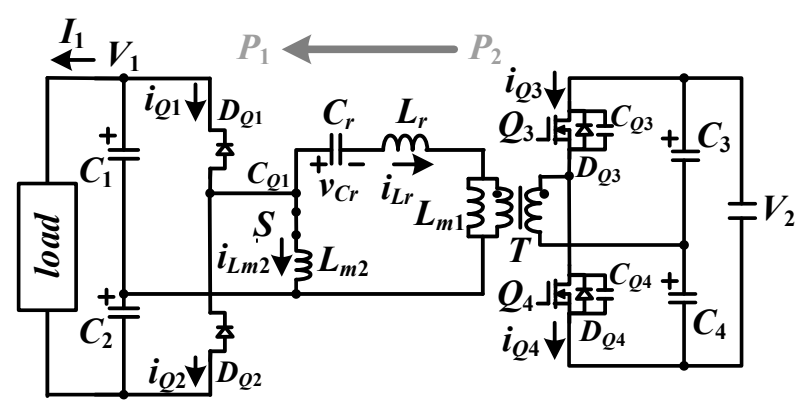

(b)
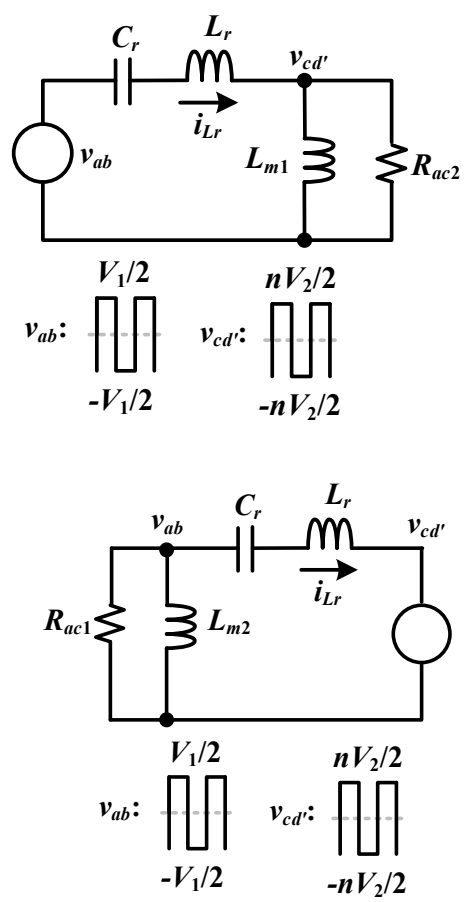

Figure 2. Circuit operation: (a) power flow from $V_{1}$ to $V_{2} ;$ (b) power flow from $V_{2}$ to $V_{1}$.

\subsection{Forward Power Flow}

The studied dual half-bridge converter can achieve bidirectional power flow capability. When power is transferred from high-voltage $V_{1}$ to low-voltage $V_{2}$, battery banks or super capacitors can be adopted as energy storage units on the low-voltage terminal. The circuit configuration of the adopted dual half-bridge converter under forward power flow is shown in Figure 2a. The ac switch $S$ is off under forward power flow. $Q_{1}$ and $Q_{2}$ are worked as the main switches to generate a square wave voltage on voltage $v_{a b}$. $Q_{3}$ and $Q_{4}$ are operated as synchronous rectifiers to lessen conducting losses on the low-voltage side. According to the polarity of the secondary side current, a square wave voltage is generated on voltage $v_{c d^{\prime}} . L_{m 1}$ is the magnetizing inductance of the transformer; $L_{r}$ and $C_{r}$ are the resonant inductor and capacitor. $Q_{1}$ and $Q_{2}$ are controlled by using frequency modulation to regulate load current $I_{2}$ or voltage $V_{2}$. Due to the resonant operation by $L_{r}, C_{r}$, and $L_{m 1}$, the soft switching operation of $Q_{1}$ and $Q_{2}$ can be realized. Figure 3a demonstrates the basic PWM signals of the studied converter under forward power flow operation. If the series resonant frequency is higher (or lower) than the operating frequency, there are six (or four) operation stages per switching cycle as shown in Figure $3 b-g$. The circuit operations of the studied circuit under forward power flow are presented in the following. 


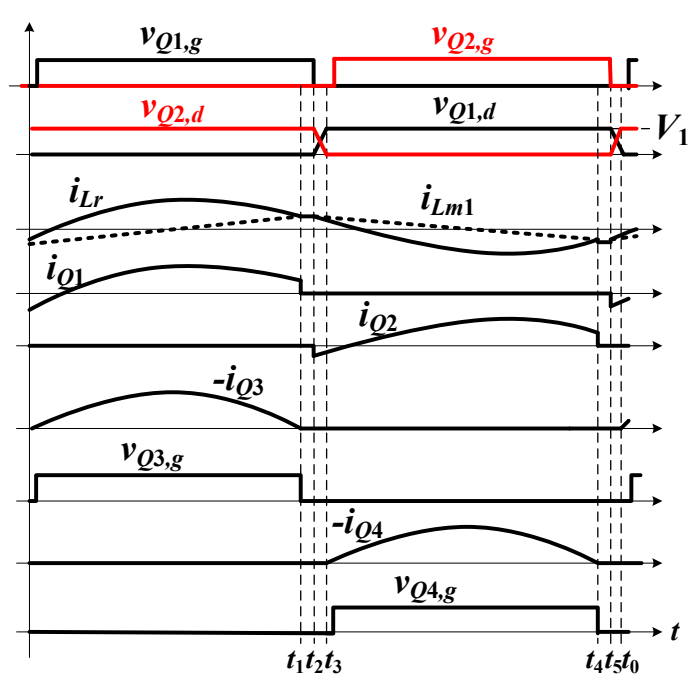

(a)

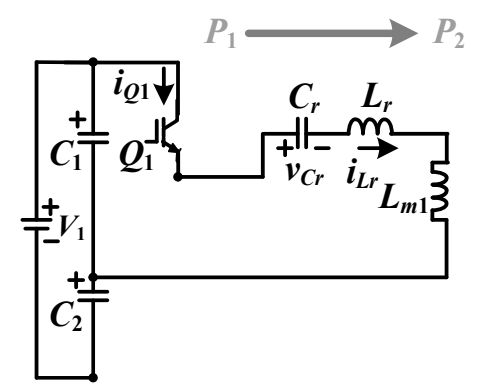

(c)

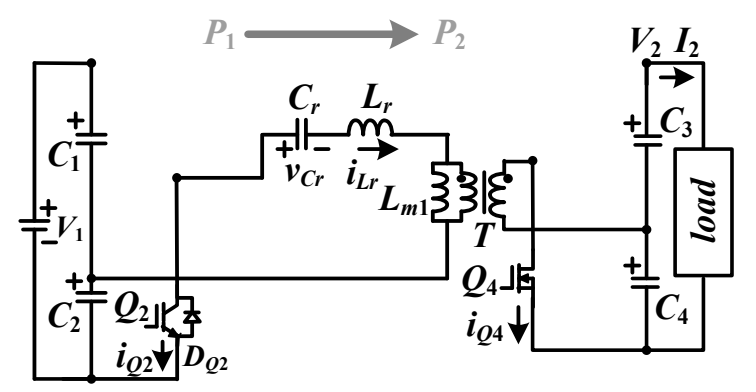

(e)

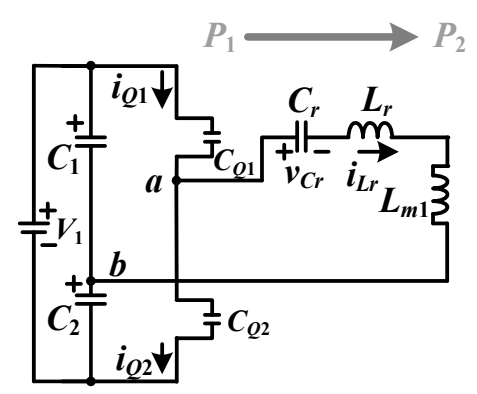

(g)

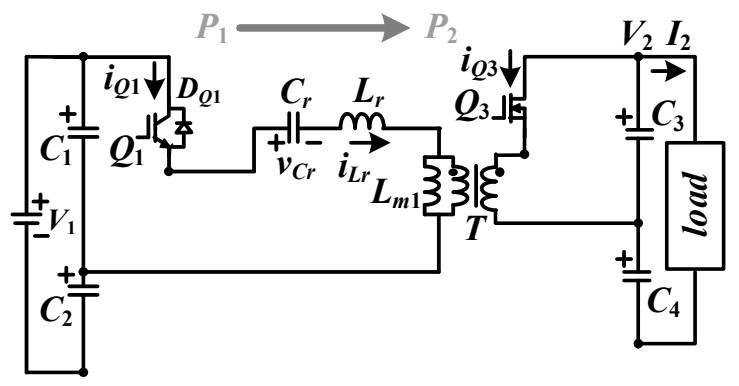

(b)
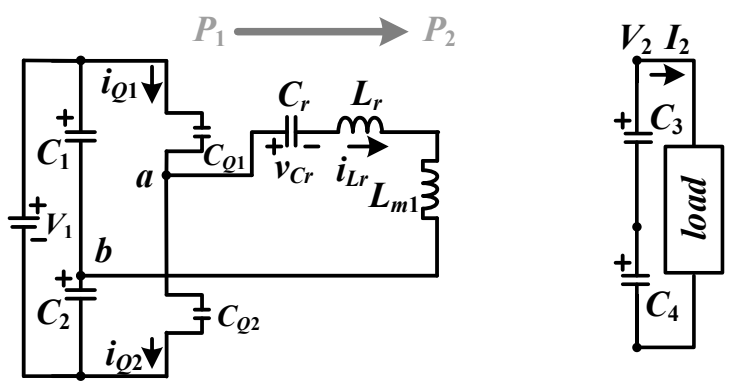

(d)
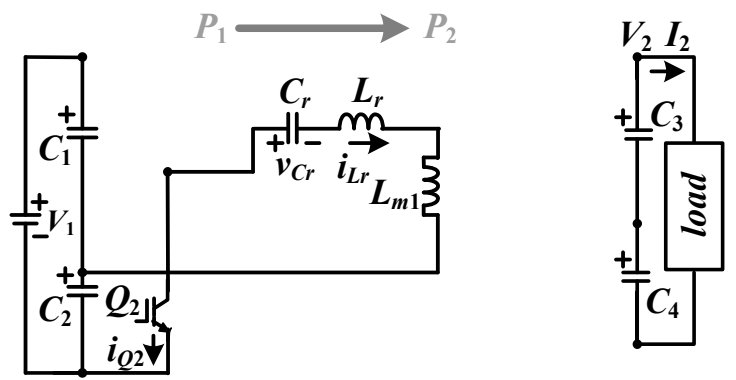

(f)

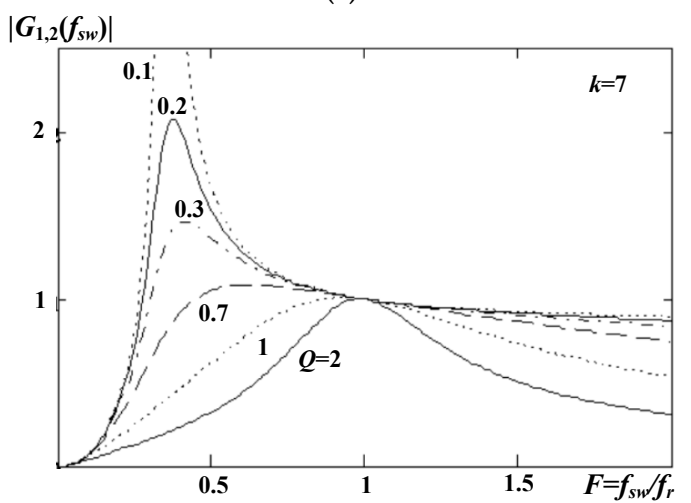

(h)

Figure 3. Pulse-width modulation (PWM) waveforms, stage operations, and gain curve under forward power flow: (a) PWM waveforms; (b) Stage 1; (c) Stage 2; (d) Stage 3; (e) Stage 4; (f) Stage 5; (g) Stage 6; (h) gain curve of the studied circuit. 
Stage $1\left(t_{0} \sim t_{1}\right)$ : The output voltage of $C_{Q 1}$ is decreased to zero at $t_{0}$. Therefore, the soft switching characteristic of $Q_{1}$ can be achieved after $t_{0}$ due to $i_{Q 1}\left(t_{0}\right)=i_{L r}\left(t_{0}\right)<0$ and $D_{Q 1}$ conducts. Since $i_{L r}>i_{L m 1}$ and $i_{Q 3}<0, Q_{3}$ is turned on and the secondary side current flows through MOSFET $Q_{3}$ turn-on resistor $R_{o n}$ to charge capacitor $C_{3}$. Due to low turn-on resistance $R_{o n}$, the conduction losses on the low-voltage side can be reduced compared to using a fast recovery diode. The ac side voltages of the two half-bridge circuits are $v_{a b}=V_{C 1}=V_{1} / 2$ and $v_{c d}=V_{C 3}=V_{2} / 2$. Thus, the primary magnetizing voltage $v_{L m 1}=v_{c d^{\prime}}=$ $n V_{2} / 2$ and the magnetizing current $i_{L m 1}$ increase with the current slope $n V_{2} /\left(2 L_{m 1}\right)$. The magnetizing current variation in Stage 1 is about $\Delta i_{L m 1,1}=n V_{2} \Delta t_{10} /\left(2 L_{m 1}\right)$ where $\Delta t_{10}$ is the time interval in Stage 1. $C_{r}$ and $L_{r}$ are resonant in Stage 1 under $v_{a b}=V_{1} / 2, v_{L m 1}=n V_{2} / 2$ and $f_{r}=1 / 2 \pi \sqrt{C_{r} L_{r}}$. If $f_{r}>f_{s w}$, then $T_{r} / 2<T_{s w} / 2$. Therefore, the transformer secondary current will decrease to zero before $Q_{1}$ turns off. The circuit operation goes to Stage 2. If $f_{r}<f_{s w}$, then $T_{r} / 2>T_{s w} / 2$. When $Q_{1}$ turns off, the secondary winding current is still positive. Then, the circuit operation goes to Stage 3.

Stage $2\left(t_{1} \sim t_{2}\right):$ If $f_{r}>f_{s w}$, the transformer secondary current decreases to zero before $Q_{1}$ turns off. When $i_{Q 3}$ equals zero at $t_{1}, Q_{3}$ turns off. $i_{L r}$ flows through $Q_{1}, C_{r}, L_{r}, L_{m 1}$, and $C_{1}$. Since $C_{1} \gg C_{r}$, components $C_{r}, L_{r}$, and $L_{m 1}$ are resonant under $v_{a b}=V_{1} / 2$ and resonant frequency $f_{p}=1 / 2 \pi \sqrt{C_{r}\left(L_{r}+L_{m 1}\right)}$. When $t=T_{s w} / 2$, switch $Q_{1}$ turns off and the circuit operation of Stage 2 is completed.

Stage $3\left(t_{2} \sim t_{3}\right)$ : When $t=t_{2}=T_{s w} / 2, Q_{1}$ turns off, and $C_{Q 1}\left(C_{Q 2}\right)$ is charged (discharged) by $i_{L r}$. In order to ensure that $Q_{2}$ turns on at zero voltage, the zero-voltage condition of $Q_{2}$ is calculated using

$$
i_{\text {Lm1,peak }} \geq \frac{V_{1}}{2} \sqrt{\frac{2 C_{Q}}{L_{m 1}+L_{r}}}
$$

where $C_{Q}=C_{Q 1}=C_{Q 2}$. The maximum magnetizing current is estimated using Equation (2).

$$
i_{L m 1, p e a k}=\frac{\Delta i_{L m}}{2} \approx \frac{n V_{2}}{8 L_{m 1} f_{s w}}
$$

The time interval in Stage 3 can be estimated as follows when $C_{Q_{2}}$ is discharged to zero voltage:

$$
\Delta t_{23}=\frac{2 V_{1} C_{Q}}{i_{L r}\left(t_{2}\right)} \approx \frac{2 V_{1} C_{Q}}{i_{L m 1, p e a k}}=\frac{16 L_{m 1} f_{s w} V_{1} C_{Q}}{n V_{2}} \leq t_{\text {dead }}
$$

where $t_{\text {dead }}$ is the dead time between $Q_{1}$ and $Q_{2}$. Based on Equation (3), the maximum magnetizing inductance $L_{m 1}$ can be calculated using Equation (4).

$$
L_{m 1} \leq \frac{t_{\text {dead }} n V_{2}}{16 f_{s w} V_{1} C_{Q}}
$$

Stage $4\left(t_{3} \sim t_{4}\right)$ : The voltage of $C_{Q 2}$ is decreased to zero at $t_{3}$. The body diode $D_{Q 2}$ conducts due to $i_{L r}\left(t_{3}\right)>0$ (or $i_{Q 2}\left(t_{3}\right)<0$ ). After time $t_{3}$, the soft switching characteristic of $Q_{2}$ can achieved. Since the secondary side current $i_{Q 4}$ is negative, $Q_{4}$ is forced to turn on to decrease conduction loss. Then, the ac side voltage $v_{c d}=-V_{2} / 2$, the magnetizing voltage $v_{L m 1}=-n V_{2} / 2$, and $i_{L m 1}$ decreases. The magnetizing current variation in Stage 2 is about $\Delta i_{L m 1,4}=n V_{2} \Delta t_{34} /\left(2 L_{m 1}\right)$ where $\Delta t_{34}$ is the time interval in Stage 4. In Stage 4, $C_{r}$ and $L_{r}$ are resonant under $v_{a b}=-V_{1} / 2, v_{L m 1}=-n V_{2} / 2$ and $f_{r}=1 / 2 \pi \sqrt{C_{r} L_{r}}$. If $f_{r}>f_{s w}$, the circuit operation goes to Stage 5 . If $f_{r}<f_{s w}$, the circuit operation goes to Stage 6.

Stage $5\left(t_{4} \sim t_{5}\right)$ : If $f_{r}>f_{s w}, i_{Q 4}$ will go to zero before $Q_{2}$ turns off. When $i_{Q 4}$ equals zero at $t_{4}, Q_{4}$ is forced to turn off. In Stage $5, i_{L r}$ flows through $Q_{2}, C_{r}, L_{r}, L_{m 1}$, and $C_{2}$. Components $C_{r}, L_{r}$, and $L_{m 1}$ are resonant under $v_{a b}=-V_{1} / 2$ with resonant frequency $f_{p}=1 / 2 \pi \sqrt{C_{r}\left(L_{r}+L_{m 1}\right)}$. When $Q_{2}$ turns off, the circuit operation goes to Stage 6 . 
Stage $6\left(t_{5} \sim T_{s w}+t_{0}\right)$ : When $Q_{2}$ turns off at $t_{5}, C_{Q 1}\left(C_{Q 2}\right)$ is discharged (charged) by $i_{L r}\left(t_{5}\right)<0$. To ensure that $Q_{1}$ turns on at zero voltage, the zero-voltage condition of $Q_{1}$ is the same as that of $Q_{2}$. The time interval in this stage is short enough to be neglected in state-state analysis. At time $T_{s w}+t_{0}$, the voltage of $C_{Q 1}$ decreases to zero voltage and the circuit operation of this stage is completed.

To derive the transfer function of the studied converter under forward power flow, a fundamental frequency approach is adopted to derive the ac voltage gain. According to the on/off states of $Q_{1} \sim Q_{4}$, the square voltage waveforms are obtained on voltages $v_{a b}$ and $v_{c d}$. Since the resonant tank of $L_{r}, C_{\mathrm{r}}$, and $L_{m 1}$ is worked as a band pass filter, the harmonic frequency on $v_{a b}$ and $v_{c d}$ can be neglected to simplify the characteristic analysis. The root mean square $(r m s)$ values of $v_{a b}$ and $v_{c d}$ at the switching frequency are $\sqrt{2} V_{1} / \pi$ and $\sqrt{2} V_{2} n / \pi$, respectively. The equivalent resistance at the primary side of transformer can be calculated as $R_{a c 2}=2 n^{2} R_{0} / \pi^{2}$. The equivalent circuit of the adopted resonant tank is shown in Figure 2a. The effectively fundamental sinusoidal voltage is $v_{a b, f}$ with $r m s$ voltage value $\sqrt{2} V_{1} / \pi$ and the resonant tank consists of $L_{r}, C_{r}, L_{m 1}$, and $R_{a c 2}$. The voltage transfer function between low-voltage $V_{2}$ and high-voltage $V_{1}$ is derived in Equation (5).

$$
G_{1,2}(s) \mid=\frac{v_{R_{a c 2}}(s)}{v_{a b, f}(s)}=\frac{\frac{s L_{m 1} R_{a c 2}}{s L_{m 1}+R_{a c 2}}}{\frac{1}{s C_{r}}+s L_{r}+\frac{s L_{m 1} R_{a c 2}}{s L_{m 1}+R_{a c 2}}}
$$

The amplitude of the voltage transfer function in Equation (5) can be obtained using Equation (6):

$$
\left|G_{1,2}\left(f_{s w}\right)\right|=\frac{k F^{2}}{\sqrt{\left[(k+1) F^{2}-1\right]^{2}+\left[Q k F\left(F^{2}-1\right)\right]^{2}}}
$$

where $f_{r}=1 /\left(2 \pi \sqrt{L_{r} C_{r}}\right), Q=\sqrt{L_{r} / C_{r}} / R_{a c 2}, k=L_{m 1} / L_{r}$, and $F=f_{s w} / f_{r}$. Based on the input voltage $V_{1}$, output voltage $V_{2}$, inductor ratio $k$, and load resistance $R_{a c 2}$, the necessary switching frequency can be calculated from Equation (6). The gain curve of the proposed converter under forward power flow is plotted in Figure 3 under inductor ratio $k=L_{m 1} / L_{r}=7$.

\subsection{Reverse Power Flow}

The power flow of the studied dual half-bridge circuit can also be delivered from low-voltage $V_{2}$ to high-voltage $V_{1}$ as shown in Figure $2 \mathrm{~b}$. Under this condition, the ac switch $S$ is turned on, $Q_{3}$ and $Q_{4}$ are operated as the main power switch to generate a square voltage waveform on voltage $v_{c d}$, and the primary voltage $v_{L m 1} \approx n v_{c d}=v_{c d^{\prime}} \cdot Q_{1}$ and $Q_{2}$ are off and the antiparallel diodes $D_{Q 1}$ and $D_{Q 2}$ are operated as the full-wave rectifiers. According to the polarity of $i_{Q 1}$ and $i_{Q 2}$, a square wave voltage is generated on voltage $v_{a b} . L_{r}, C_{r}$, and $L_{m 2}$ are activated as the resonant tank to realize an inductive load operation. Therefore, the soft switching characteristic of main power devices $Q_{3}$ and $Q_{4}$ can be achieved. $Q_{3}$ and $Q_{4}$ are controlled with frequency modulation to regulate current $I_{1}$ or voltage $V_{1}$. Figure 4 demonstrates the PWM waveforms and the equivalent circuit of the studied converter under reverse power flow.

Stage $1\left(t_{0} \sim t_{1}\right): C_{Q 3}$ is discharged to zero voltage at $t_{0}, i_{L r}>0$, and $i_{Q 3}<0$. The soft switching characteristic of $Q_{3}$ is realized when $Q_{3}$ is turned on after $t_{0}$. Since $-i_{L r}>i_{L m 2}$ and $i_{Q 1}<0, D_{Q 1}$ conducts and $C_{1}$ is charged by $-i_{Q 1}$. In Stage 1 , the ac side voltages are $v_{a b}=V_{C 1}=V_{1} / 2$ and $v_{c d}=V_{C 3}=V_{2} / 2$. $i_{L m 2}$ increases with the current slope $V_{1} /\left(2 L_{m 2}\right) . C_{r}$ and $L_{r}$ are resonant in Stage 1 under $v_{a b}=V_{1} / 2$, $v_{L m 1}=n V_{2} / 2$, and $f_{r}=1 / 2 \pi \sqrt{C_{r} L_{r}}$. If $f_{r}>f_{s w}$, the circuit operation goes to the next stage. If $f_{r}<f_{s w}$, the circuit operation goes to Stage 3. Power is transferred in this stage from $V_{2}$ to $V_{1}$ through $Q_{3}, T, L_{r}$, $C_{r}$, and $D_{Q 1}$.

Stage $2\left(t_{1} \sim t_{2}\right)$ : When $i_{D Q 1}$ is decreased to zero at $t_{1}, D_{Q 1}$ is reverse biased. $i_{L r}$ flows through $S, C_{r}, L_{r}, T$, and $L_{m 2} . C_{r}, L_{r}$, and $L_{m 2}$ are resonant under $v_{L m 1}=n V_{2} / 2$ and resonant frequency $f_{p}=1 / 2 \pi \sqrt{C_{r}\left(L_{r}+L_{m 2}\right)}$. When $t=t_{2}, Q_{3}$ turns off and the circuit operation of Stage 2 is completed. 


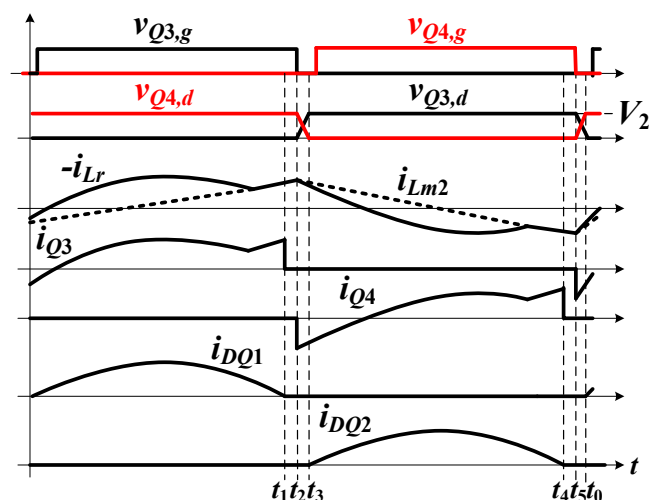

(a)
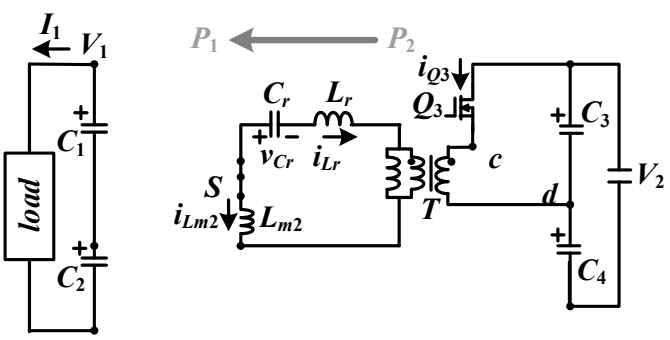

(c)

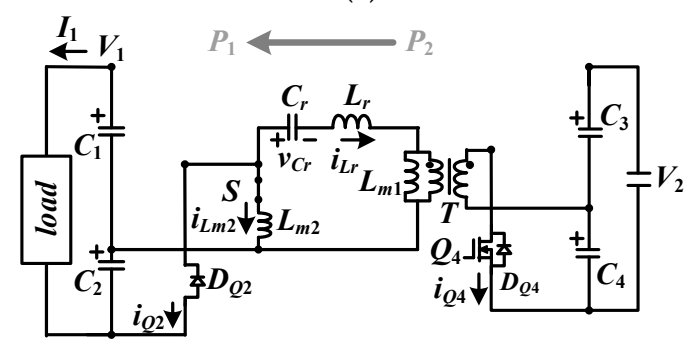

(e)
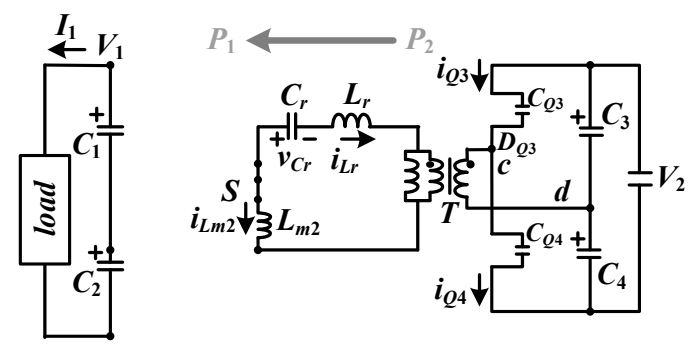

(g)

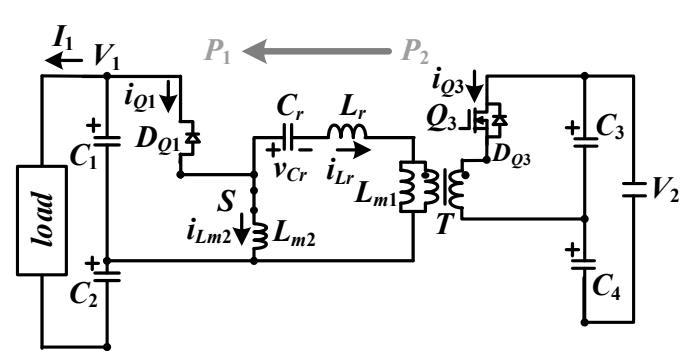

(b)
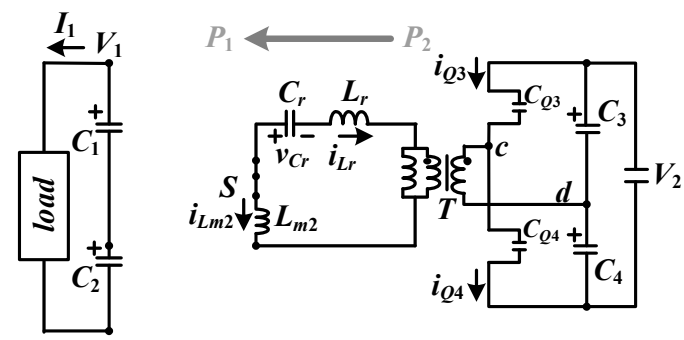

(d)
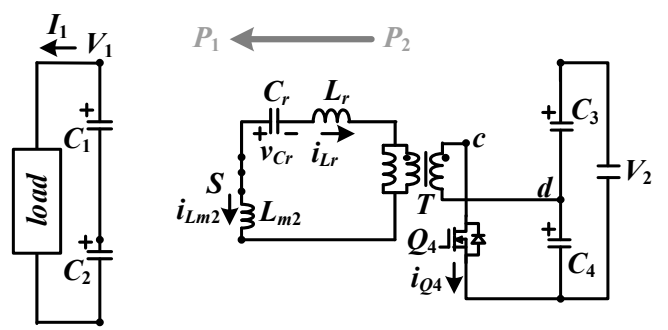

(f)

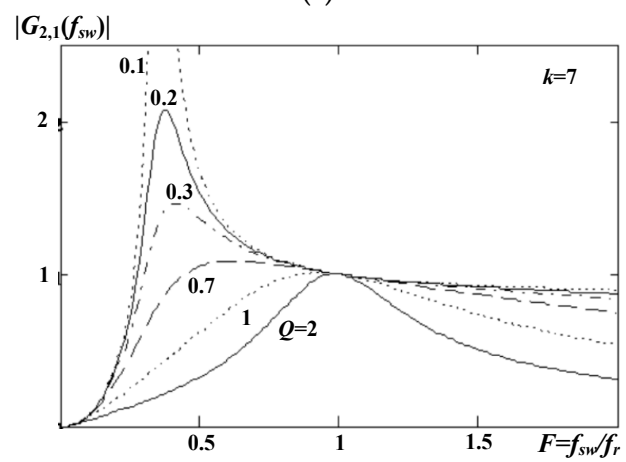

(h)

Figure 4. PWM waveforms, stage operations, and gain curve under reverse power flow: (a) PWM waveforms; (b) Stage 1; (c) Stage 2; (d) Stage 3; (e) Stage 4; (f) Stage 5; (g) Stage 6; (h) gain curve of the studied circuit.

Stage $3\left(t_{2} \sim t_{3}\right): Q_{3}$ turns off at time $t_{2}$. Since $i_{L r}<0, C_{Q 3}\left(C_{Q 4}\right)$ is charged (discharged). In order to ensure that $Q_{4}$ turns on at zero voltage, the zero-voltage condition of $Q_{4}$ is calculated in Equation (7):

$$
i_{\text {Lm2,peak }} \geq \frac{V_{2}}{2} \sqrt{\frac{2 C_{Q, s}}{L_{m 2}+L_{r}}}
$$

where $C_{Q, s}=C_{Q 3}=C_{Q 4}$. The peak values of $i_{L m 1}$ and $i_{L m 2}$ can be calculated as 


$$
\begin{gathered}
i_{\text {Lm1,peak }}=\frac{\Delta i_{L m 1}}{2} \approx \frac{V_{2}}{8 L_{m 1} f_{s w}} \\
i_{\text {Lm2,peak }}=\frac{\Delta i_{L m 2}}{2} \approx \frac{V_{1}}{8 L_{m 2} f_{s w}} .
\end{gathered}
$$

The time interval in Stage 3 can be estimated when $C_{Q 4}$ is discharged to zero voltage:

$$
\Delta t_{23}=\frac{2 V_{2} C_{Q, s}}{n\left[i_{L m 1}\left(t_{2}\right)+i_{L m 2}\left(t_{2}\right)\right]} \approx \frac{2 V_{2} C_{Q, s}}{n\left[i_{L m 1, p e a k}+i_{L m 2, p e a k}\right]}=\frac{16 L_{m 1} L_{m 2} f_{s w} V_{2} C_{Q, s}}{n\left(L_{m 2} V_{2}+L_{m 1} V_{1}\right)} \leq t_{\text {dead }}
$$

where $t_{\text {dead }}$ is the dead time between $Q_{3}$ and $Q_{4}$.

Stage $4\left(t_{3} \sim t_{4}\right): C_{Q 4}$ is discharged to zero at $t_{3}$. The body diode $D_{Q 4}$ of $Q_{4}$ conducts due to the fact that $i_{D 4}\left(t_{3}\right)<0$. Therefore, the soft switching characteristic of $Q_{4}$ can achieved after time $t_{3}$. In Stage 4 , $i_{Q 2}$ is negative and $D_{Q 2}$ conducts. Therefore, $v_{a b}=-V_{1} / 2$ and $v_{c d}=-V_{2} / 2$. $C_{r}$ and $L_{r}$ are resonant with resonant frequency $f_{r}=1 / 2 \pi \sqrt{C_{r} L_{r}}$. If $f_{r}>f_{s w}$, the circuit operation goes to Stage 5 . If $f_{r}<f_{s w}$, the circuit operation goes to Stage 6 .

Stage $5\left(t_{4} \sim t_{5}\right)$ : If $f_{r}>f_{s w}, i_{Q 2}$ will go to zero before $Q_{4}$ is turned off. When $i_{D Q 2}$ equals zero at $t_{4}$, $D_{Q 2}$ is reverse biased. In Stage $5, i_{L r}$ flows through $C_{r}, L_{r}, T$, and $L_{m 2}$. Components $C_{r}, L_{r}$, and $L_{m 2}$ are resonant under $v_{c d}=-V_{2} / 2$ with resonant frequency $f_{p}=1 / 2 \pi \sqrt{C_{r}\left(L_{r}+L_{m 2}\right)}$. When $Q_{4}$ turns off at $t_{5}$, the circuit operation goes to Stage 6 .

Stage $6\left(t_{5} \sim T_{s w}+t_{0}\right)$ : When $Q_{4}$ turns off at $t_{5}, C_{Q 3}\left(C_{Q 4}\right)$ is discharged (charged). The time interval in Stage 6 can be neglected in state-state analysis. At time $T_{s w}+t_{0}$, the voltage of $C_{Q 3}$ is decreased to zero and the circuit operation of Stage 6 is completed.

The transfer function of the studied circuit under reverse power flow is similar to that under forward power flow operation. $Q_{3}$ and $Q_{4}$ are the main active devices and $D_{Q 1}$ and $D_{Q 2}$ are worked as the full-wave diode rectifier. The circuit characteristic of $L_{r}, C_{r}$, and $L_{m 2}$ (instead of $L_{m 1}$ ) is like a band pass filter to filter the harmonic current. Figure $2 b$ gives the equivalent circuit of the adopted resonant tank. The effectively fundamental sinusoidal voltage is $v_{c d^{\prime}, f}$ with rms voltage value $\sqrt{2} V_{2} n / \pi$, and the resonant tank consists of $L_{r}, C_{r}, L_{m 2}$, and $R_{a c 1}$. The equivalent resistance at the high-voltage side is calculated as $R_{a c 1}=2 R_{o} / \pi^{2}$. The voltage transfer function between high-voltage $V_{1}$ and low-voltage $V_{2}$ is derived in Equation (11).

$$
G_{2,1}(s) \mid=\frac{v_{R_{a c 1}}(s)}{v_{c d 1, f}(s)}=\frac{\frac{s L_{m 2} R_{a c 1}}{s L_{m 2}+R_{a c 1}}}{\frac{1}{s C_{r}}+s L_{r}+\frac{s L_{m 2} R_{a c 1}}{s L_{m 2}+R_{a c 1}}}
$$

Likewise, the amplitude of the voltage transfer function in Equation (11) can be calculated using Equation (12):

$$
\left|G_{2,1}\left(f_{s w}\right)\right|=\frac{k F^{2}}{\sqrt{\left[(k+1) F^{2}-1\right]^{2}+\left[Q k F\left(F^{2}-1\right)\right]^{2}}}
$$

where $f_{r}=1 /\left(2 \pi \sqrt{L_{r} C_{r}}\right), Q=\sqrt{L_{r} / C_{r}} / R_{a c 1}, k=L_{m 2} / L_{r}$, and $F=f_{s w} / f_{r}$. Based on $V_{1}, V_{2}, k$, and $R_{a c 1}$, the necessary switching frequency can be obtained from Equation (12). The gain curve of the proposed converter under reverse power flow is plotted in Figure $4 \mathrm{~h}$ under inductor ratio $k=L_{m 2} / L_{r}=7$.

\section{Design Procedure of the Studied Converter}

The design procedure with a laboratory prototype is discussed and presented in this section to demonstrate the practicability of the studied bidirectional dual half-bridge converter. The voltage range at high voltage is from $350 \mathrm{~V}$ to $400 \mathrm{~V}$ and the voltage range at the low-voltage side is from $38 \mathrm{~V}$ to $52 \mathrm{~V}$. The rated power of the prototype circuit is $480 \mathrm{~W}$. When the proposed circuit is worked under forward power flow, $V_{2}$ is controlled at $48 \mathrm{~V}$. If the proposed circuit is worked under reverse power flow, $V_{1}$ is controlled at $400 \mathrm{~V}$. Since the circuit characteristics of the proposed converter under forward 
and reverse power flow are similar, only the design procedure of the prototype circuit under forward power flow is discussed in the following. The transformer turn ratio is calculated using Equation (13) under maximum input and output voltages and $G_{1,2}=1$.

$$
n=\left|G_{1,2}\right| \times \frac{V_{1, \max }}{V_{2, \max }}=1 \times \frac{400}{52} \approx 7.7
$$

The actual primary and secondary winding turns are 24 turns and 3 turns, respectively. Therefore, the minimum and maximum dc gains are determined using Equations (14) and (15), respectively, under nominal output voltage.

$$
\begin{aligned}
\left|G_{1,2}\right|_{d c, \text { min }} & =n \times \frac{V_{2, \text { nom }}}{V_{1, \text { max }}}=\frac{24}{3} \times \frac{48}{400} \approx 0.96 \\
\left|G_{1,2}\right|_{d c, \text { max }} & =n \times \frac{V_{2, \text { nom }}}{V_{1, \text { min }}}=\frac{24}{3} \times \frac{48}{350} \approx 1.097
\end{aligned}
$$

The select inductor ratio $k$ and quality factor $Q$ are based on the necessary maximum dc gain $\left|G_{1,2}\right|_{d c, \max }=1.097$. The maximum gain of the proposed converter under the selected $k=7$ and $Q=0.6$ is about 1.35, which is greater than $\left|G_{1,2}\right|_{d c, \max }=1.097$. Based on the selected turn ratio, the equivalent resistance $R_{a c 2}$ at full load is determined from Equation (16).

$$
R_{a c 2}=\frac{2 n^{2}}{\pi^{2}} R_{o}=\frac{2 \times(24 / 3)^{2}}{3.14159^{2}} \times \frac{48}{10} \approx 62.25 \Omega
$$

The resonant parameters $C_{r}$ and $L_{r}$ are calculated from Equations (17) and (18) under the series resonant frequency $f_{r}=100 \mathrm{kHz}$ and full load.

$$
\begin{gathered}
C_{r}=\frac{1}{2 \pi Q f_{r} R_{a c 2}}=\frac{1}{2 \pi \times 0.6 \times 100 \times 10^{3} \times 62.25} \approx 42.6 \mathrm{nF} \\
L_{r}=\frac{1}{\left(2 \pi f_{r}\right)^{2} C_{r}}=\frac{1}{\left(2 \pi \times 100 \times 10^{3}\right)^{2} \times 42.6 \times 10^{-9}} \approx 59.5 \mu \mathrm{H}
\end{gathered}
$$

The actual resonant parameters used in the prototype are $C_{r}=42 \mathrm{nF}$ and $L_{r}=60 \mu \mathrm{H}$. The magnetizing inductance $L_{m 1}$ is determined from Equation (19).

$$
L_{m 1}=k L_{r}=7 \times 60=420 \mu \mathrm{H}
$$

The primary side rms load current is calculated in Equation (20).

$$
I_{r m s, p}=\frac{\pi I_{o}}{\sqrt{2} n}=\frac{\pi \times 10}{\sqrt{2} \times(24 / 3)}=2.777 \mathrm{~A}
$$

The minimum switching frequency is determined in Equation (21).

$$
f_{s w, \text { min }}=f_{p}=\frac{1}{2 \pi \sqrt{C_{r}\left(L_{r}+L_{m 1}\right)}}=\frac{1}{2 \pi \sqrt{42 \times 10^{-9} \times(60+420) \times 10^{-6}}} \approx 35.45 \mathrm{kHz}
$$

The rms magnetizing current of transformer $T$ at $f_{s w, \min }$ under minimum switching frequency is calculated in Equation (22).

$$
I_{L m 1, r m s}=\frac{1}{2 \sqrt{3}} \frac{n V_{2}}{4 f_{s w, \min } L_{m 1}}=\frac{1}{2 \sqrt{3}} \times \frac{(24 / 3) \times 48}{4 \times 35.45 \times 10^{3} \times 420 \times 10^{-6}} \approx 1.86 \mathrm{~A}
$$


The rms values of the resonant inductor current $I_{L r, r m s}$ and the primary winding current $I_{p r i, T}$ under minimum switching frequency and full load are calculated and expressed in Equation (23).

$$
I_{p r i, T}=I_{L r, r m s}=\sqrt{I_{L m 1, r m s}^{2}+I_{r m s, p}^{2}}=\sqrt{1.86^{2}+2.77^{2}} \approx 3.34 \mathrm{~A}
$$

The rms value of the secondary winding current $I_{s e c, T}$ is given as

$$
I_{\mathrm{sec}, T}=n i_{r m s, p}=(24 / 3) \times 2.777=22.21 \mathrm{~A} .
$$

The peak voltage of the resonant capacitor $C_{r}$ under minimum switching frequency and full load is calculated in Equation (25).

$$
v_{C r, p e a k}=\sqrt{2} I_{L r, r m s} X_{C r}=\frac{\sqrt{2} I_{L r, r m s}}{2 \pi f_{s w, \min } C_{r}}=\frac{\sqrt{2} \times 3.34}{2 \pi \times 35.45 \times 10^{3} \times 42 \times 10^{-9}} \approx 505 \mathrm{~V}
$$

The voltage stresses of $Q_{1}$ and $Q_{2}$ are equal to $V_{1}=400 \mathrm{~V}$, and the voltage stresses of $Q_{3}$ and $Q_{4}$ are equal to $V_{2, \max }=52 \mathrm{~V}$. The current stresses of $Q_{1} \sim Q_{4}$ are calculated in Equations (26) and (27).

$$
\begin{aligned}
& I_{Q 1, r m s}=I_{Q 2, r m s}=I_{L r, r m s} / \sqrt{2}=3.34 / \sqrt{2} \approx 2.36 \mathrm{~A} \\
& I_{Q 3, r m s}=I_{Q 4, r m s}=I_{\mathrm{sec}, T} / \sqrt{2}=22.21 / \sqrt{2} \approx 15.7 \mathrm{~A}
\end{aligned}
$$

The insulated gate bipolar transistor (IGBT) IRG4PC40W with $600 \mathrm{~V} / 20$ A rating with less switching losses and higher switching frequency operation were adopted for switches $Q_{1}$ and $Q_{2}$ and MOSFETs IRFB4321PbF with $150 \mathrm{~V} / 85 \mathrm{~A}$ rating were adopted for switches $Q_{3}$ and $Q_{4}$. The ac switch $S$ was implemented using two MOSFETs SiHG20N50C with $500 \mathrm{~V} / 20$ A rating with back-to-back connection. The selected inductor $L_{m 2}=180 \mu \mathrm{H}$ gives inductor ratio $k=L_{m 2} / L_{r}=3$ under reverse power flow operation from $V_{2}$ to $V_{1}$. The adopted input and output capacitances are $C_{1}=C_{2}=180 \mu \mathrm{F} /$ $400 \mathrm{~V}$ and $C_{3}=C_{4}=2200 \mu \mathrm{F} / 100 \mathrm{~V}$.

\section{Experimental Results}

Based on the circuit parameters derived from the previous section, a $480 \mathrm{~W}$ prototype circuit was tested to validate the practicability of the studied converter. Figures 5-8 demonstrate the test results under forward power flow operation. Figure 5 shows the test results of $Q_{1}$ at $20 \%$ load and full load. The test results show that $Q_{1}$ turns on at zero voltage for both $20 \%$ and $100 \%$ loads. Likewise, Figure 6 demonstrates test results of $Q_{2}$ under different load conditions. It is observed that the soft switching turn-on characteristics of $Q_{2}$ are also achieved. Figure 7 demonstrates the measured waveforms of the resonant voltage and resonant current. The test results show that the switching frequency is close to the series resonant frequency under $400 \mathrm{~V}$ input. Thus, the resonant current is close to a sinusoidal waveform. On the other hand, the series resonant frequency is greater than the switching frequency under the $350 \mathrm{~V}$ input case. Figure 8 demonstrates the test results of the secondary side currents and capacitor voltages. The output capacitor voltages $V_{C 3}$ and $V_{C 4}$ are balanced and the switch currents $-i_{Q 3}$ and $-i_{Q 4}$ are also balanced. Figures $9-11$ demonstrates test results of the studied converter under reverse power flow. The soft switching characteristics of $Q_{3}$ and $Q_{4}$ are given in Figures 9 and 10 and the resonant voltage and current are demonstrated in Figure 11. Figure 12 shows the measured circuit efficiencies of the studied circuit. The efficiencies of the proposed converter under forward power flow and $V_{1}=400 \mathrm{~V}$ are $95.2 \%, 95.7 \%$, and $93.6 \%$ under $20 \%, 50 \%$, and $100 \%$ loads, respectively. The efficiencies of the proposed converter under reverse power flow and $V_{2}=52 \mathrm{~V}$ are $89.7 \%, 91.5 \%$, and $91.2 \%$ under $20 \%, 50 \%$, and $100 \%$ loads, respectively. The proposed converter has better circuit efficiency under forward power flow due to the fact that MOSFETs are used on the low-voltage side to reduce the conduction losses. The measured switching frequencies of the proposed converter under forward power flow are $138 \mathrm{kHz}$ (or $84 \mathrm{kHz}$ ), $114 \mathrm{kHz}$ (or $79 \mathrm{kHz}$ ), and $99 \mathrm{kHz}$ (or $71 \mathrm{kHz}$ ) under 
$400 \mathrm{~V}$ (or $350 \mathrm{~V}$ ) input and 20\% load, 50\% load, and 100\% load output, respectively. Lower input voltage results in low switching frequency and the switching frequency is increased when the dc load is decreased. Figure 13 gives a picture of the experimental setup and a photo of the proposed converter in the laboratory test.

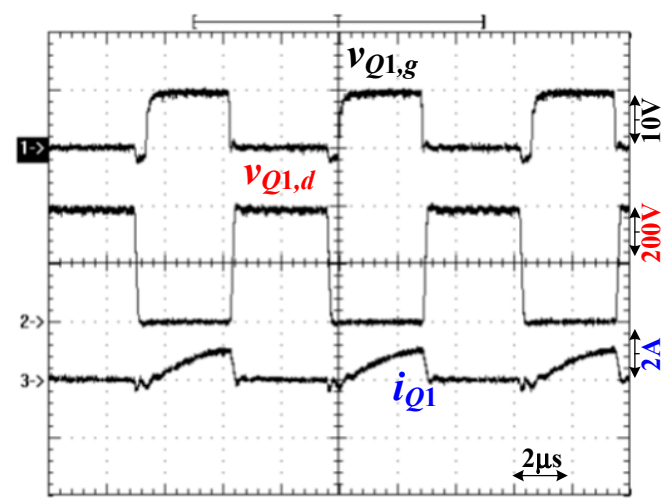

(a)

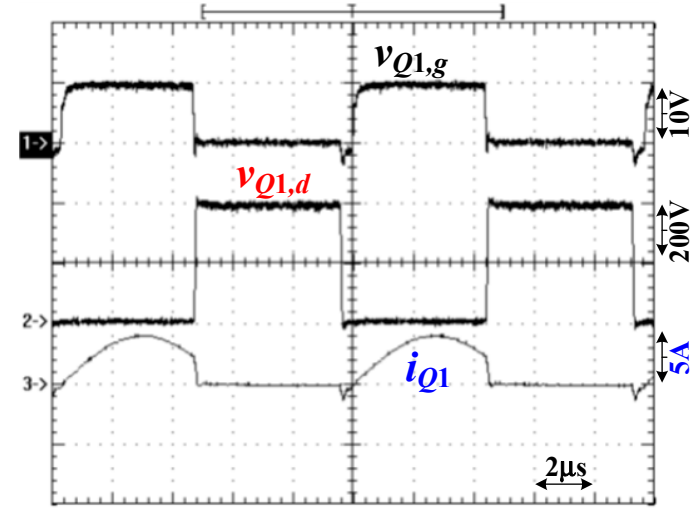

(b)

Figure 5. Test results of switch $Q_{1}$ under $V_{1}=400 \mathrm{~V}$ with (a) $96 \mathrm{~W}$ (20\%) output and (b) $480 \mathrm{~W}$ $(100 \%)$ output.

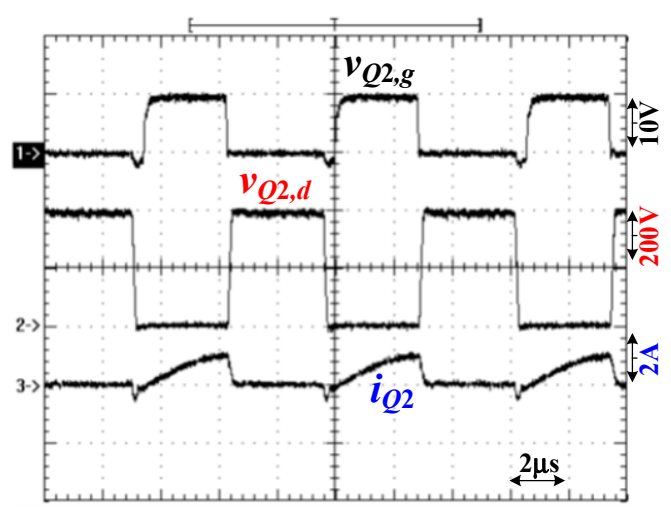

(a)

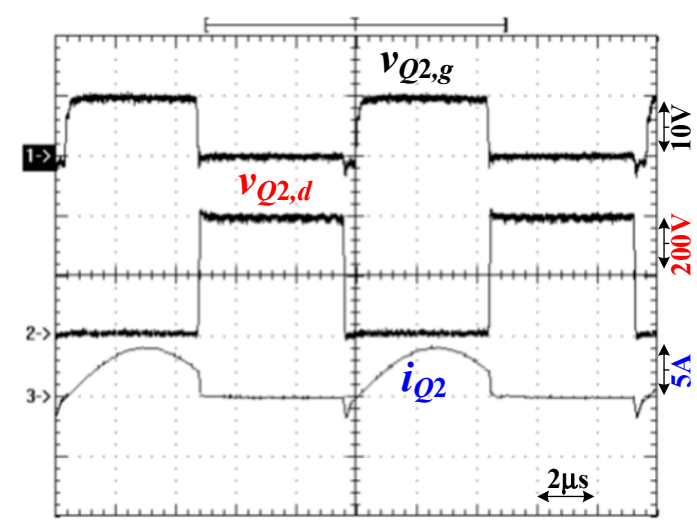

(b)

Figure 6. Test results of switch $Q_{2}$ under $V_{1}=400 \mathrm{~V}$ with (a) $96 \mathrm{~W}(20 \%)$ output and (b) $480 \mathrm{~W}$ $(100 \%)$ output.

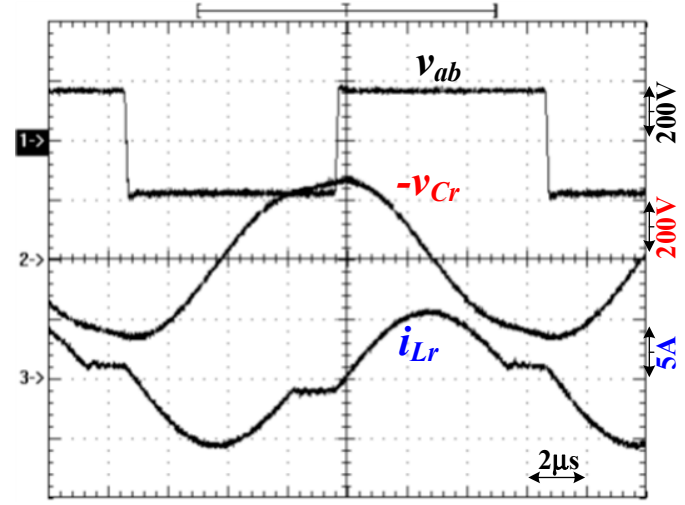

(a)

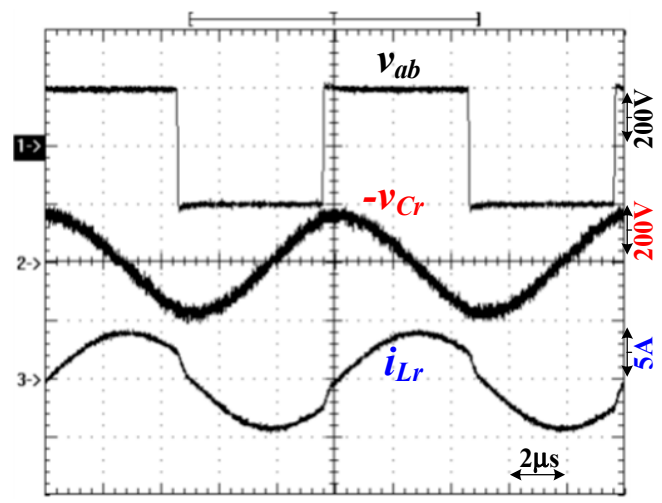

(b)

Figure 7. Test results of $v_{a b},-v_{C r}$, and $i_{L r}$ under $480 \mathrm{~W}$ output with (a) $V_{1}=350 \mathrm{~V}$ and (b) $V_{1}=400 \mathrm{~V}$. 


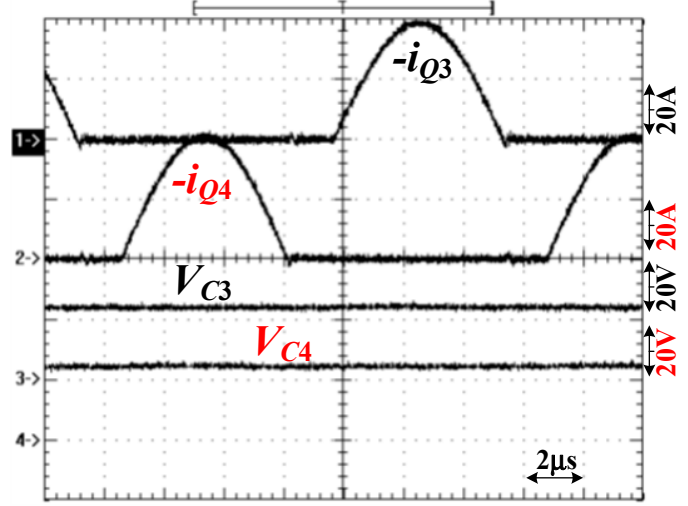

(a)

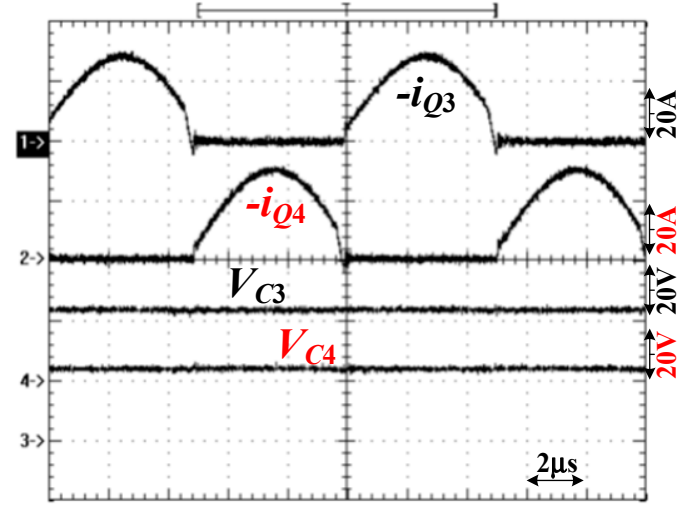

(b)

Figure 8. Test results of $-i_{Q 3},-i_{Q 4}, V_{C 3}$, and $V_{C 4}$ under $480 \mathrm{~W}$ output with (a) $V_{1}=350 \mathrm{~V}$ and (b) $V_{1}=400 \mathrm{~V}$.

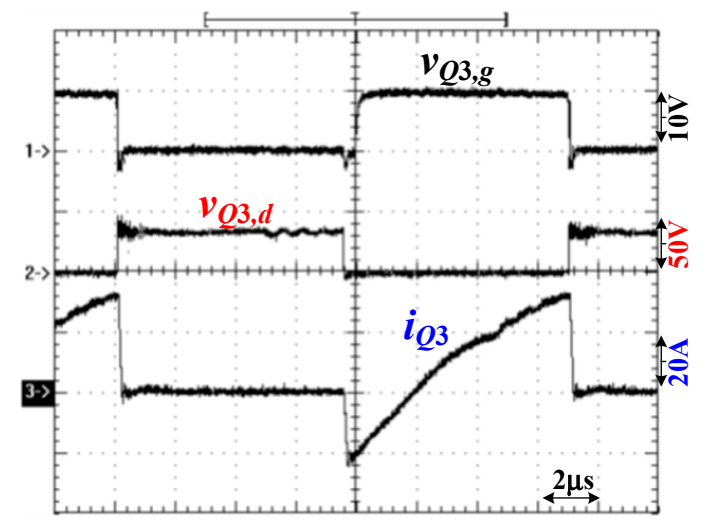

(a)

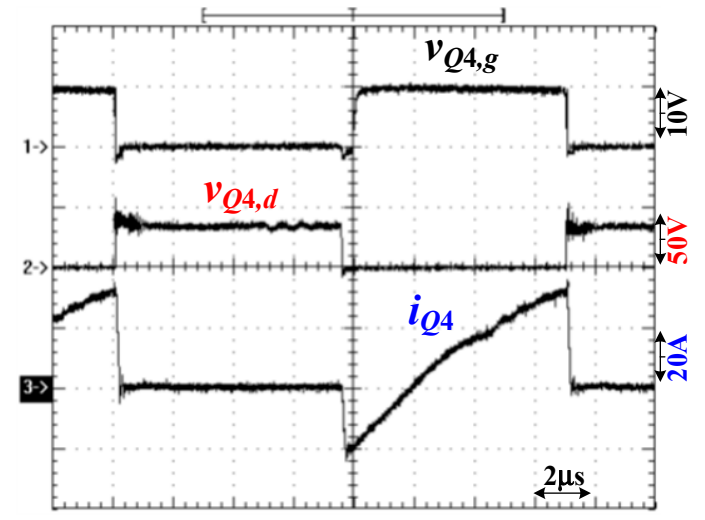

(c)

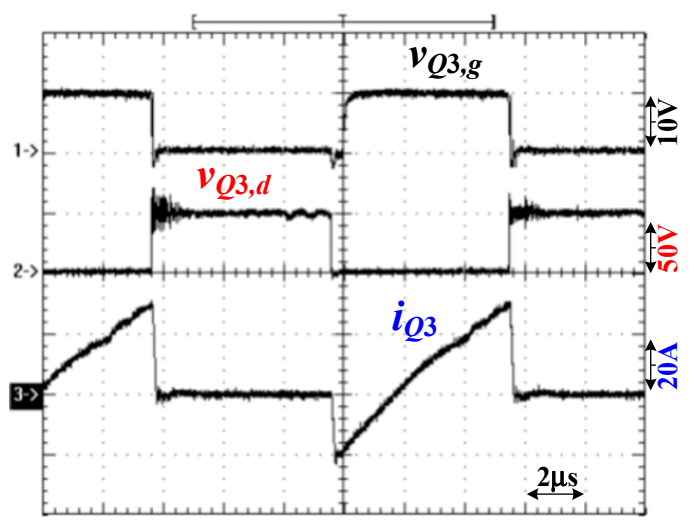

(b)

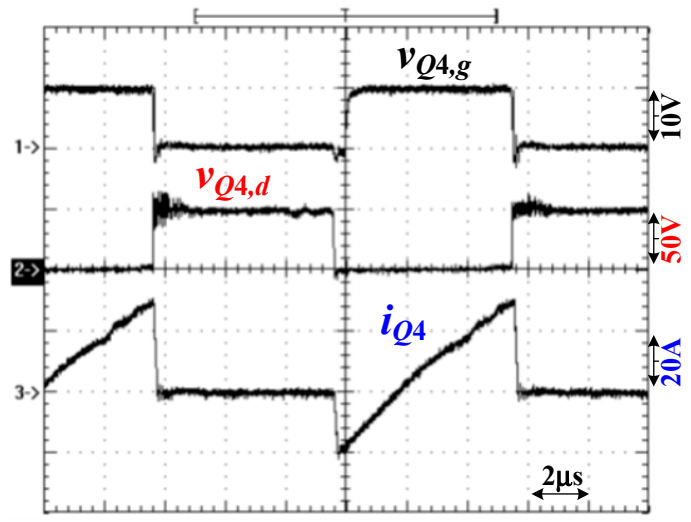

(d)

Figure 9. Test results of $Q_{3}$ and $Q_{4}$ under reverse power flow and 96W (20\% load) output with (a) $Q_{3}$ at $V_{2}=38 \mathrm{~V}$, (b) $Q_{3}$ at $V_{2}=52 \mathrm{~V}$, (c) $Q_{4}$ at $V_{2}=38 \mathrm{~V}$, and (d) $Q_{4}$ at $V_{2}=52 \mathrm{~V}$. 


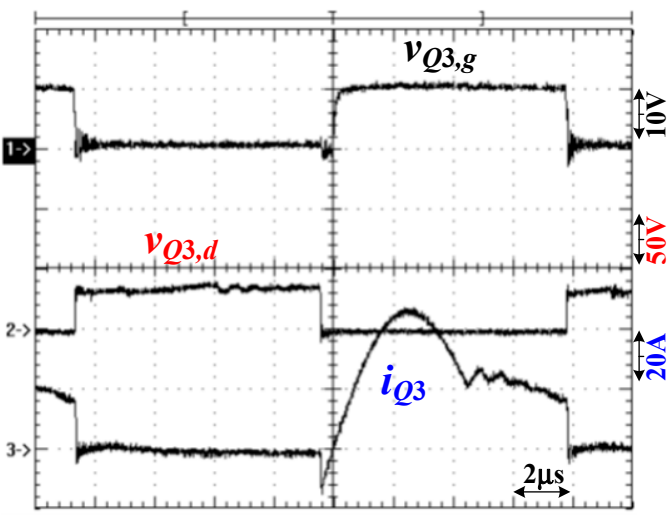

(a)

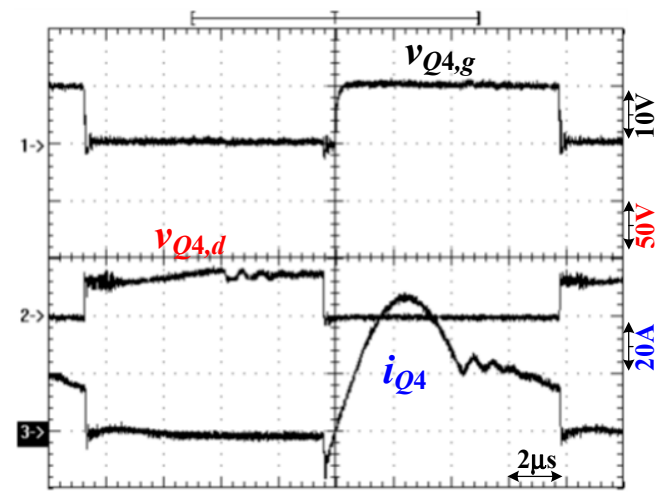

(c)

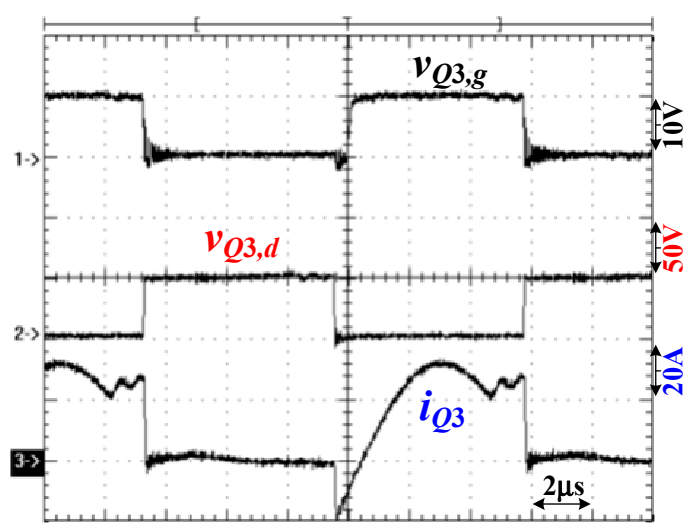

(b)

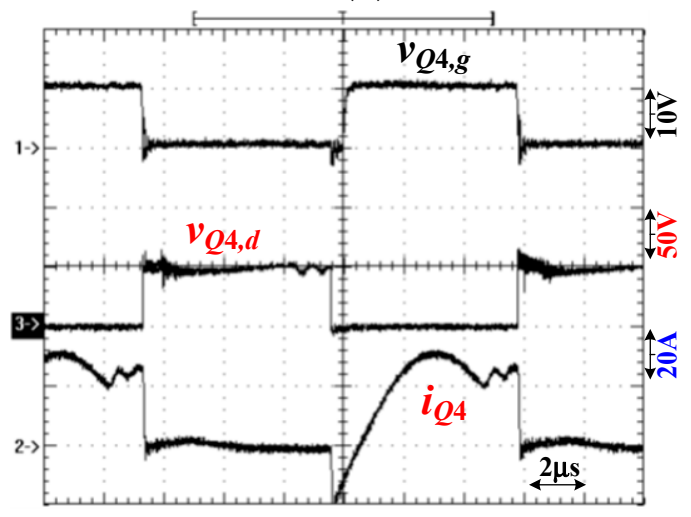

(d)

Figure 10. Test results of $Q_{3}$ and $Q_{4}$ under reverse power flow and $480 \mathrm{~W}$ (100\% load) output with (a) $Q_{3}$ at $V_{2}=38 \mathrm{~V}$, (b) $Q_{3}$ at $V_{2}=52 \mathrm{~V}$, (c) $Q_{4}$ at $V_{2}=38 \mathrm{~V}$, and (d) $Q_{4}$ at $V_{2}=52 \mathrm{~V}$.

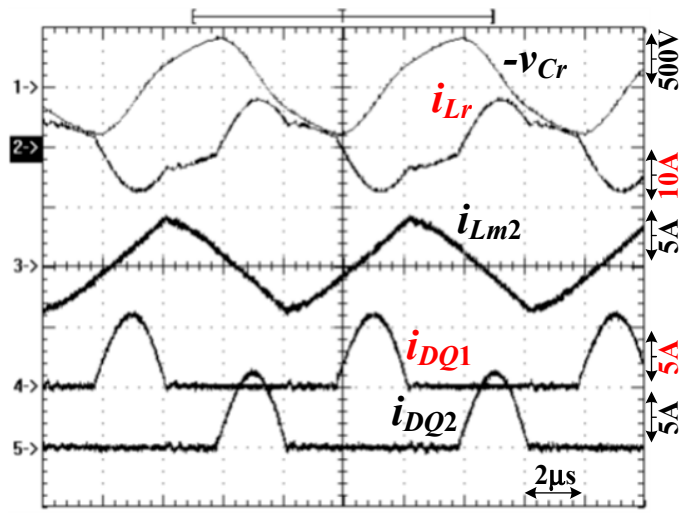

(a)

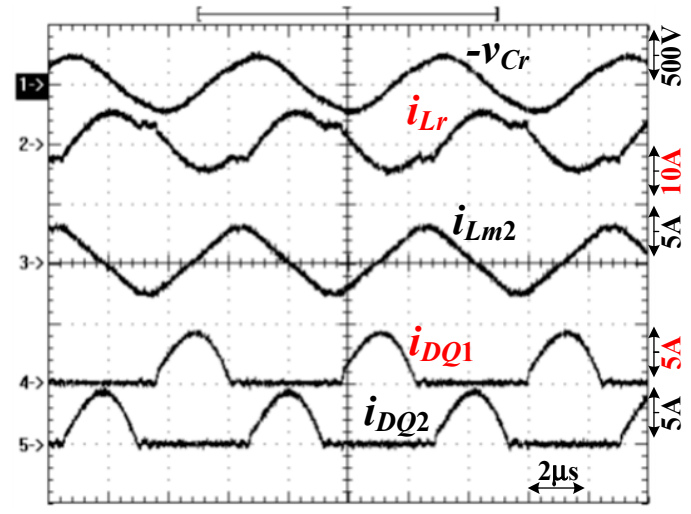

(b)

Figure 11. Test results of $-v_{C r}, i_{L r}, i_{L m 2}, i_{D Q 1}$, and $i_{D Q 2}$ under reverse power flow and $480 \mathrm{~W}$ output with (a) $V_{2}=38 \mathrm{~V}$ and (b) $V_{2}=52 \mathrm{~V}$. 


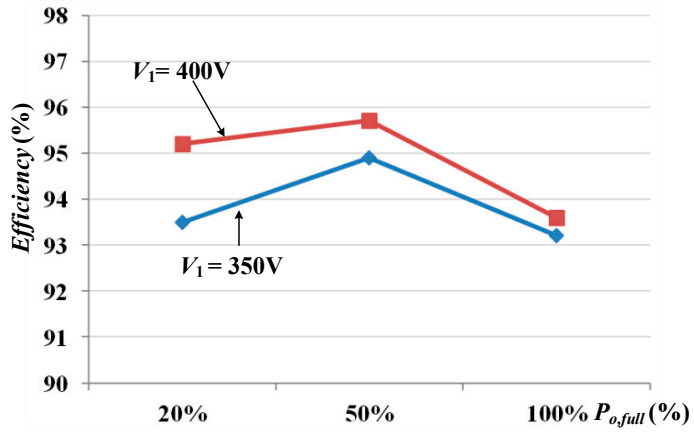

(a)

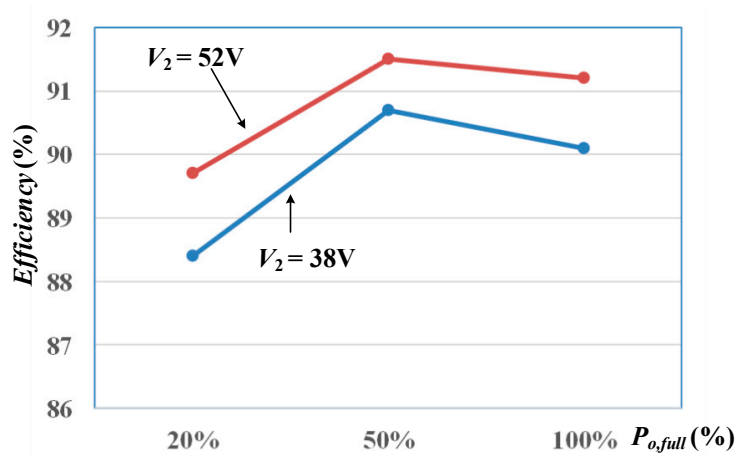

(b)

Figure 12. Measured circuit efficiencies of the studied converter under (a) forward power flow and (b) reverse power flow.

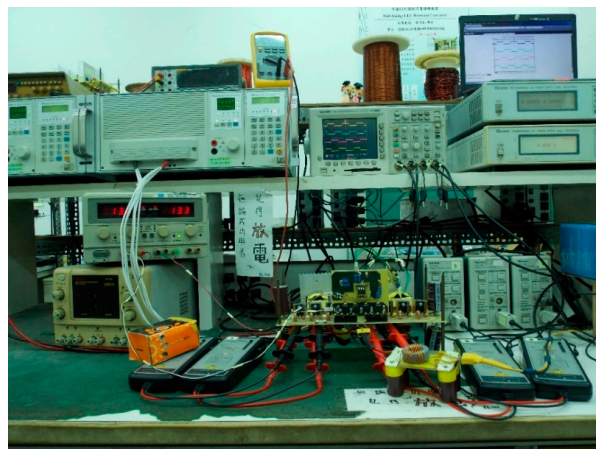

(a)

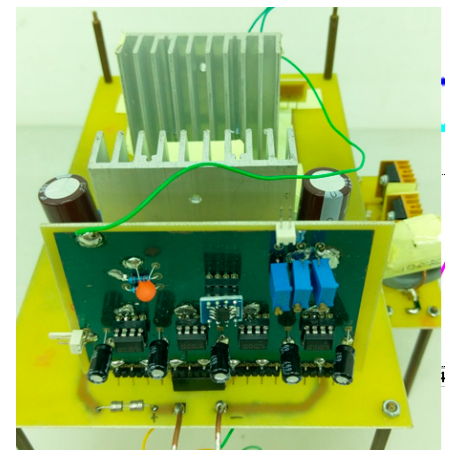

(b)

Figure 13. Pictures of the studied converter in the laboratory: (a) experimental setup, (b) prototype circuit.

\section{Conclusions}

This paper studied a resonant converter constructed using a dual half-bridge circuit to realize bidirectional power flow. Two half-bridge circuits were used on the high- and low-voltage sides to clamp the voltage rating of the active devices at input and output voltages. A series resonant tank was adopted on the primary side of the isolated transformer to realize soft switching characteristics of the power devices. A frequency control scheme was adopted to control the switching frequency so that the voltage gain of the resonant tank is adjustable and the load voltage can be controlled. A laboratory prototype of the design was built and the test results demonstrated the feasibility of the studied circuit.

Author Contributions: B.-R.L. designed the main parts of the project and was also responsible for writing the paper. G.-Y.W. built the prototype circuit and measured test results.

Funding: Ministry of Science and Technology, Taiwan, under contract MOST 105-2221-E-224-043-MY2.

Acknowledgments: This study is supported by the Ministry of Science and Technology, Taiwan, under contract MOST 105-2221-E-224-043-MY2.

Conflicts of Interest: The authors declare no conflict of interest.

\section{References}

1. Meng, L.; Shafiee, Q.; Trecate, G.F.; Karimi, H.; Fulwani, D.; Lu, X.; Guerrero, J.M. Review on control of DC microgrids and multiple microgrid clusters. IEEE J. Emerg. Sel. Top. Power Electron. 2017, 5, 928-948.

2. Mai, T.D.; Broeck, G.V.D.; Pevere, A.; Driesen, J. Power electronics for potential distribution dc power evolution: A review. In Proceedings of the 2016 IEEE International Energy Conference (ENERGYCON), Leuven, Belgium, 4-8 April 2016; pp. 1-6. 
3. Jing, W.; Lai, C.H.; Wong, S.H.W.; Wong, M.L.D. Battery-super capacitor hybrid energy storage system in standalone dc microgrids: A review. IET Proc. Renew. Power Gener. 2017, 11, 461-469. [CrossRef]

4. Dragicevic, T.; Lu, X.; Vasquez, J.C.; Guerrero, J.M. DC microgrids-part I: A review of control strategies and stabilization techniques. IEEE Trans. Power Electron. 2016, 31, 4876-4891. [CrossRef]

5. Guerrero, J.M.; Loh, P.C.; Lee, T.L.; Chandorkar, M. Advanced control architectures for intelligent microgrids-part II: Power quality, energy storage, and ac/dc microgrids. IEEE Trans. Ind. Electron. 2013, 60, 1263-1270. [CrossRef]

6. Yilmaz, M.; Krein, P.T. Review of battery charger topologies, charging power levels, and infrastructure for plug-in electric and hybrid vehicles. IEEE Trans. Power Electron. 2013, 28, 2151-2169. [CrossRef]

7. Emadi, A.; Lee, Y.J.; Rajashekara, K. Power electronics and motor drives in electric, hybrid electric, and plug-in hybrid electric vehicles. IEEE Trans. Ind. Electron. 2008, 55, 2237-2245. [CrossRef]

8. Chan, C.C.; Chau, K.T. An overview of power electronics in electric vehicles. IEEE Trans. Ind. Electron. 1997, 44, 3-13. [CrossRef]

9. Ahrabi, R.R.; Ardi, H.; Elmi, M.; Ajami, A. A novel step-up multi input dc-dc converter for hybrid electric vehicles application. IEEE Trans. Ind. Electron. 2017, 32, 3549-3561.

10. Xu, D.; Zhao, C.; Fan, H. A PWM plus phase-shift control bidirectional DC-DC converter. IEEE Trans. Power Electron. 2004, 19, 666-675. [CrossRef]

11. Li, H.; Peng, F.Z.; Lawler, J.S. A natural ZVS medium-power bidirectional DC-DC converter with minimum number of devices. IEEE Trans. Ind. Appl. 2003, 39, 525-535. [CrossRef]

12. Tao, H.; Kotsopoulos, A.; Duarte, J.L.; Hendrix, M.A.M. Family of multiport bidirectional DC-DC converters. IEE Proc. Electr. Power Appl. 2006, 153, 451-458. [CrossRef]

13. Zhang, Y.; Gao, Y.; Li, J.; Sumner, M. Interleaved switched-capacitor bidirectional dc-dc converter with wide voltage-gain range for energy storage systems. IEEE Trans. Power Electron. 2018, 33, 3852-3869. [CrossRef]

14. Mangu, B.; Akshatha, S.; Suryanarayana, D.; Fernandes, B.G. Grid-connected PV-wind-battery-based multi-input transformer-couple bidirectional dc-dc converter for household applications. IEEE J. Emerg. Sel. Top. Power Electron. 2016, 4, 1086-1095. [CrossRef]

15. Shen, C.L.; Shen, Y.S.; Chiu, P.C.; Liang, T.C. Isolated bidirectional converter with minimum active switches for high-voltage ratio achievement and micro-grid applications. IET Proc. Power Electron. 2017, 10, 2208-2216. [CrossRef]

16. Pledl, G.; Tauer, M.; Buecherl, D. Theory of operation, design procedure and simulation of a bidirectional LLC resonant converter for vehicular applications. In Proceedings of the IEEE Vehicle Power and Propulsion Conference (VPPC), Lille, France, 1-3 September 2010; pp. 1-5.

17. Tan, K.; Yu, R.; Guo, S.; Huang, A.Q. Optimal design methodology of bidirectional LLC resonant DC/DC converter for solid state transformer application. In Proceedings of the IEEE IECON Conference, Dallas, TX, USA, 30 October-1 November 2014; pp. 1657-1664.

18. Kim, E.S.; Park, J.H.; Jeon, Y.S.; Kong, Y.S.; Lee, S.M.; Kim, K. Bidirectional Secondary LLC Resonant Converter using Auxiliary Switches and Inductor. In Proceedings of the IEEE APEC Conference, Fort Worth, TX, USA, 16-20 March 2014; pp. 1941-1947.

19. Jiang, T.; Zhang, J.; Wu, X.; Sheng, K.; Wang, Y. A Bidirectional LLC Resonant Converter With Automatic Forward and Backward Mode Transition. IEEE Trans. Power Electron. 2015, 30, 757-770. [CrossRef]

(C) 2018 by the authors. Licensee MDPI, Basel, Switzerland. This article is an open access article distributed under the terms and conditions of the Creative Commons Attribution (CC BY) license (http://creativecommons.org/licenses/by/4.0/). 